\title{
PASADO, PRESENTE Y FUTURO DE LA ARQUITECTURA ESPAÑOLA CONTEMPORÁNEA
}

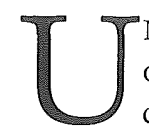

NA GRAN EXPOSICIÓN de carácter antológico sobre la obra de Antonio Fernández Alba se ha inaugurado recientemente en las salas del Museo Español de Arte Contemporáneo con el patrocinio del Centro de Promoción de las Artes Plásticas e Instituto de Investigación de las Nuevas Formas Expresivas del Ministerio de Cultura. Destaquemos, en principio, el que esta exposición se celebre tras clausurar otra dedicada al también arquitecto J. A. Coderch de Sentmenat, lo que permite abrigar ciertas esperanzas sobre la posibilidad de incorporar, por fin, de manera seria y sistemática, la arquitectura contemporánea al programa oficial de exposiciones. Se llena de esta manera un vacío injustificable que impedía la contemplación y la reflexión crítica consiguiente de lo que más directamente puede afectar en cuestiones artísticas al hombre actual: la construcción y organización de su entorno cotidiano. Con estas dos exposiciones citadas y con aquellas otras que presumiblemente vayan a continuación, quizá acabemos conociendo tanto lo que ha sido como lo que pudo ser nuestro paisaje urbano: la forma en que hemos vivido y la que nos toca todavía vivir. $Y$, aunque hay muchas otras razones para justificar el interés de las exposiciones sobre arquitectura española contemporánea, no hace falta por el momento descender a más detalles.

Antonio Fernández Alba (Salamanca, 1927) es uno de nuestros arquitectos más conocidos y quizá el ejemplo más perfecto que poseemos de intelectual humanista en el contexto de profesiones técnicas. En efecto, durante los casi veinticinco años que median entre la obtención de su título de arquitecto 
(Madrid, I957) y la actualidad, la actividad creadora de Fernández Alba nunca se ha circunscrito a los límites mezquinos de una profesión entendida como coto cerrado en sí mismo, sino que ha estado abierta a todo tipo de experiencias que ha sabido integrar ejemplarmente. En este sentido, su relación viva con los movimientos plásticos de vanguardia, como lo fue, por ejemplo, su participación en el célebre grupo El Paso; su amplia actividad docente, que se corona con la obtención de la cátedra de Elementos de Composición en la Escuela de Arquitectura de Madrid; o, finalmente, su extensa labor como publicista, que suma ya varios libros y un sinnúmero de artículos y recensiones, son cosas todas ellas, al margen de su estricta trayectoria de arquitecto, que le sitúan en un punto de vista privilegiado para comprender y enjuiciar un proceso tan complejo como es el de la arquitectura contemporánea. Precisamente teniendo muy presente esa cualificación que posee para poder realizar una síntesis crítica, además naturalmente del interés testimonial de su experiencia, hemos querido hablar ampliamente con él sobre su interpretación general del fenómeno histórico de la arquitectura contemporánea en nuestro país, tanto desde el punto de vista de sus ideas y juicios sobre lo que en este campo ha ocurrido en España, como desde el punto de vista de su propia experiencia como arquitecto.

\section{LA ARQUITECTURA NACIONALISTA DE POSGUERRA}

Francisco Calvo Serraller. En tu libro La crisis de la arquitectura española, I939-1972 (Madrid, 1972), una de las primeras aproximaciones historiográficas al problema de la arquitectura española de posguerra, planteabas la existencia de una corriente nacionalista, que se inspiraba en los modelos fascistas italogermanos y que se constituyó como la primera gran alternativa arquitectónica del nuevo régimen franquista. Esta cuestión, la de la existencia o no de un estilo artístico del régimen, pero, sobre todo, la de su valoración estética e ideológica, ha dado pie últimamente a una amplia literatura polémica de muy desigual calidad. Por lo general, la mayor parte de esta literatura crítica llenaba su gran vacío documental y su incapacidad de análisis para interpretar científicamente el hecho arquitectónico 
con adhesiones emocionales y afirmaciones ideológicas de carácter tendencioso. Estos últimos años, sin embargo, un grupo joven de historiadores y críticos de arquitectura ha renovado los estudios sobre el tema y nos está ofreciendo una visión del mismo que cambia sustancialmente la actitud tópica tradicional. La exposición Arquitecturas para después de una guerra o la serie de publicaciones que han realizado al respecto Antón Capitel, Carlos Sambricio, L. Doménech, Quetglás, Ignasi Solá Morales, etc., nos pueden servir de ejemplo concreto de esta nueva actitud. Pues bien, quiero preguntarte dos cosas al respecto: ¿a qué crees que responde esta nueva revisión crítica? y ¿cómo interpretas el fenómeno histórico mismo de la arquitectura nacionalista de posguerra?

Antonio Fernández Alba. Respecto a la primera pregunta, he de decirte que es un tema que hay que encuadrarlo dentro de las coordenadas de la crítica más contemporánea, que está interesada en el debate general de la recuperación histórica. En cuanto al problema de la arquitectura española de posguerra, a mi juicio tiene que ver con unas circunstancias muy concretas: la negación de los planteamientos racionalistas de preguerra, consecuencia de los mecanismos ideológicos del nuevo régimen, la necesidad de utilizar un lenguaje arquitectónico afín a su ideología y utiliza los dos modelos más inmediatos que dispone, los modelos de la arquitectura fascista italiana y la de la Alemania nazi. Precisando aún más, habría que referirse, por ejemplo, dentro del modelo italiano, a obras concretas como la de un Piacentini, en el caso alemán, a la interpretación que hizo A. Speer de la arquitectura neoclásica de Schinkel, tal y como se puso de manifiesto en las grandes ordenaciones de las ciudades alemanas. De todas formas, en la imposición de estos modelos no creo que se pueda hablar de unas directrices programadas; no existieron, ni condicionamientos específicos, ni normas, sino que simplemente era una actitud que estaba dentro de la mentalidad de la época, se pretendía crear una nueva imagen e indudablemente estos decorados y escenarios se prestaban a ello.

Respecto al impacto que entonces recibimos los grupos jóvenes en este período, yo recuerdo muy especialmente la gran exposición sobre arquitectura alemana, celebrada en el palacio de exposiciones del Retiro, donde se recogían los proyectos más espectaculares de la arquitectura nazi: plazas, avenidas, etc. 
Quedaba patente la recuperación, sobre todo, de los grandes postulados neoclásicos, que después, con otras versiones y otras modalidades, vuelven a incidir sobre nuestro panorama.

En España, esta arquitectura la realizaron en general unos buenos profesionales con capacidad para ejecutar correctamente los proyectos. La prueba de ello la tenemos en los poblados de Regiones Devastadas, por ejemplo, pueblos como Belchite, Teruel, etc., y, sobre todo, en los poblados de nueva planta de los alrededores de Madrid. Estaban muy bien construidos según las tipologías rurales precedentes: la gran plaza, el ayuntamiento, la iglesia, etc., con unas ordenaciones verdaderamente espléndidas para lo que más tarde tendríamos que contemplar.

F. C. S. ¿A quién elegirías como el arquitecto más representativo de este momento?

A. F. A. A Luis Moya, que sintetiza este período de recuperación nacionalista de una manera muy precisa por su formación clásica, sus grandes conocimientos de la historia de la arquitectura y sus excelentes dotes como dibujante y arquitecto. Luis Moya tiene además la oportunidad de realizar grandes obras de la época, como son por ejemplo las Escuelas Profesionales de San José en Zamora y la Universidad Laboral de Gijón; en esta última obra quedan representados todos los elementos programáticos de este monumentalismo. Moya aprovecha tanto el modelo nazi, entroncado en las corrientes neoclásicas de un Schinkel, como el italiano, fundamentalmente interesado en una recuperación renacentista de los postulados de los grandes tratadistas romanos. Moya, en efecto, proyecta, con una estructura compositiva neoclásica y unos conocimientos renacentistas muy importantes, a los que une aportaciones de los modelos de las grandes culturas antiguas, como puede ser, por ejemplo, el Templo de Jerusalén. Todo ello enfatizado con imágenes románticas, ya que Moya es una personalidad fundamentalmente romántica. En definitiva, es un arquitecto expresionista, un gran arquitecto incomprendido por algunos sectores, incluidos los del propio régimen. Carlos de Miguel recogió con precisión esta época en la R. N. A. y en Arquitectura.

F. C. S. El Escorial pretendía reproducir el Templo de Salomón y parece, en general, que Moya también fue sensible a influencias de la tradición vernácula, además de seguir los modelos de italianos y alemanes. En realidad, ¿crees que se 
construyó mucho siguiendo esos modelos o simplemente se proyectó? En Madrid, por ejemplo, uno se encuentra con muy pocos edificios como el de Sindicatos...

A. F. A. Efectivamente el edificio de Sindicatos de Cabrero y Aburto (el primer documento de Tendencia) es uno de los pocos que se construyen siguiendo estas imágenes inspiradas en los modelos alemán o italiano. Pero hay otros profesionales que en realidad construyen más, realizan una arquitectura más burguesa, innominada, muy próxima a las modas más inmediatas y que va evolucionando según el gusto de los tiempos. Gutiérrez Soto es quien quizá encarnara mejor esta orientación.

F. C. S. Volviendo sobre el tema de la joven crítica y su interpretación de la arquitectura española de la posguerra, me gustaría que explicaras más eso que decía al principio sobre tu relación con la crítica internacional más reciente.

A. F. A. En España el pensamiento y la cultura italiana siempre han fascinado, en política y en arte son el modelo más inmediato y más brillante que tenemos, me refiero en este momento al panorama historiográfico, fácil de entender y más aún de traducir, es una consecuencia lógica y pienso que saludable si se puede superar.

F. C. S. ¿Te refieres, por ejemplo, a la reivindicación de un arquitecto como Terragni, por seguir con el caso italiano?

A. F. A. No, en general me refería a la disposición y buena acogida que tiene lo italiano, en sus escritos, proyectos, documentos, etc. La cultura arquitectónica italiana está viva y ha iniciado desde hace algunos años una política de difusión que actualmente tiene montada una auténtica industria cultural. Por lo que se refiere a estas reivindicaciones que me preguntas, supone una actitud recuperadora. Ante el cansancio de las formas, se recurre a la historia. Hay que tener en cuenta que en España no se ha hecho historia de la arquitectura contemporánea. Los estudios que hay son episodios muy puntuales y constituyen más bien una serie de crónicas. No hay todavía una historia de estos cuarenta años de arquitectura, en parte debido a que los arquitectos han carecido de una escuela o de una orientación historiográfica que les haya preparado para ello. Para llenar este vacío, han tenido que suplirlo profesionales de otras disciplinas, como pueden ser, por ejemplo, los que proceden de Filosofía y Letras. Hay un campo muy amplio por estudiar en torno a este 
período de posguerra. No existe una taxonomía de los períodos, de las épocas, de las circunstancias. Muchos trabajos se han escrito en períodos muy críticos y su imparcialidad se hace evidente, son crónicas para la denuncia contra el sistema. Los proyectos que hemos citado antes son los más conocidos porque han sido los más aireados a un nivel ideológico y, por ello, los que han aparecido publicados más veces, pero, en realidad, no se sabe bien todavía los edificios de este tipo que hay en toda España.

Pero, como te decía, en esta corriente de recuperación del racionalismo de la inmediata posguerra, creo que no hay sino una especie de escarceo historicista y un deseo de recuperar ciertas figuras un poco olvidadas. Hasta los años cincuenta podemos afirmar que, salvo algún episodio aislado, el racionalismo está proscrito. Proyectar por aquellos años, por ejemplo, algo relacionado con el llamado estilo de la Ciudad Universitaria era peligroso, ya que, en cierto sentido, representaba recuperar las imágenes de lo que habían sido las propuestas de la República. Los arquitectos de entonces eran unas minorías que no podían, en ningún momento, conectar claramente con aquellas corrientes de preguerra. Se trataba de una situación fundamentalmente ambigua. Pero me interesa insistir al respecto que a esta situación se llegaba no por condicionamientos externos de tipo ideológico preciso, ni por unas normas concretas que dictaran cómo había que hacer los proyectos, sino que, simplemente, los arquitectos en términos generales tenían muy clara su ideología, desde el punto de vista del servicio al sistema, y respondían de una forma perfectamente natural. En cualquier caso, quiero volver a destacar su condición de profesionales con oficio capaces de realizar con corrección la construcción de los proyectos. El análisis de sus plantas resulta más dudoso, con esa obsesión por duplicar el espacio, una duplicidad a veces grotesca que llegaba a crear por ejemplo una escalera de servicio por la que no tenían que transitar normalmente más de cinco o seis personas.

\section{LA FALSA TRADICIÓN}

F. C. S. En la situación que describes, ¿cómo habría que encuadrar a esa generación que denominas en tu libro como la de la falsa tradición y a la que pertenece, por ejemplo, un Coderch? 
S. F. A. Para explicarlo correctamente habría que comenzar recordando la situación que se daba en nuestra arquitectura antes de la guerra, donde pueden analizarse tres planos muy precisos: una corriente racionalista - la del GATEPAC-, que respondía a las orientaciones racionalistas y funcionalistas europeas; otra corriente de tipo ecléctico y de carácter historicista, cuyo ejemplo patente es la Exposición Iberoamericana de Sevilla; y una tercera corriente, cuyos objetivos arquitectónicos iban tras conseguir un camino de recuperación de lo nacional. En Madrid, produce una especie de costumbrismo (Arniches y algunos más), aunque, en realidad, lo más importante es lo que hace el grupo en torno a Torroja al construir el Hipódromo de la Zarzuela.

Este esquema se intenta reproducir por los grupos de minorías en la posguerra: la corriente racionalista queda prácticamente eliminada, la corriente costumbrista es la que se apoya en los conceptos de la falsa tradición, es decir, los de una tradición adulterada: formas marginales de lo que habían sido las corrientes regionalistas de preguerra. Los arquitectos más inteligentes van en busca de unos códigos muy elementales, como son los de la arquitectura mediterránea. Este es el caso de J. A. Coderch, que se apoya en las arquitecturas anónimas, en los ejemplos de unos constructores que empleaban normas muy elementales y a partir de los cuales pueden extraerse unas formas, de espacios y secuencias de carácter muy simple. En Madrid tenemos, por ejemplo, los pueblos diseñados para el I. N. de Colonización de Fernández del Amo, que intenta recuperar la imagen popular desde una plástica de lo rural, algunas de cuyas realizaciones, como Vegaviana, resultan valiosas desde un análisis compositivo, no eran muchos más los contenidos espaciales que se solicitaban.

Esta arquitectura, en manos de arquitectos menos valiosos, se transforma en una especie de folklore de pastiche. Pero esta arquitectura no es aceptada por la nueva burocracia asentada en el poder, incapaz de introducir una reflexión crítica sobre la función ideológica de la arquitectura. 


\section{PRIMERAS TENTATIVAS RACIONALISTAS}

\section{F. C. S. ¿Qué ocurre entonces?}

A. F. A. Que se produce una apertura hacia las nuevas propuestas de los jóvenes, con la intención de ofrecer una imagen hacia el exterior. Es en aquellos momentos cuando se producen las primeras tentativas racionalistas, desarrolladas por ocho o diez arquitectos en todo el país.

Se trataba de un racionalismo ya decantado, como el que se había producido en Europa, un racionalismo, en definitiva, que ya no tenía que ver directamente con los presupuestos ideológicos protorracionalistas, sino que surgía de las necesidades técnicas de reconstrucción de la posguerra. Este racionalismo, basado en las técnicas de reconstrucción que se aplican en Europa, va a formalizar una imagen, caracterizada por una especie de simplicidad antiornamental. Este es el período en el que aquí, en Madrid, aparecen, por ejemplo, los primeros poblados dirigidos, como el de Cañorroto, o, hablando de nombres concretos de arquitectos, el momento de Fisac, Corrales, Sota, Molezún, Sáenz de Oiza, Carvajal, Vázquez de Castro, Íñiguez, García Paredes, La-Hoz, etc. Se busca la inspiración en los modelos centroeuropeos y se consigue una imagen muy liviana, tranquila, depurada de formas y con unos códigos muy simples. Se trataba de unas formas y de unos arquitectos que en nada perturbaban la realidad que vivía el país.

Desde un esquema general comparativo, el proceso sigue las siguientes pautas: en un primer momento, cuando Europa reconstruye sus ciudades con una orientación racionalista, en España se da un desarrollo de carácter populista y monumentalista; los años cincuenta permiten la entrada en nuestro país a estas nuevas corrientes, porque van a permitir realizar unas construcciones más acordes con las nuevas relaciones de producción. ¿Cómo se produce el espacio durante los diez primeros años? Indudablemente se trata de unos espacios limitados a reconstruir las ruinas de la guerra, el siguiente episodio responde ya al crecimiento de todas las ciudades en el país con todos esos grandes y desoladores ensanches, campo abonado para lo que han sido las grandes inversiones especuladoras; la historia de la arquitectura en este período está escrita en piedra y ladrillo, la otra historia de esas minorías no ha salido de los 
estudios, está oculta en los dibujos de sus proyectos. Lo intolerable se hace realidad, lo razonable y lógico se destina a la utopía.

F. C. S. Como ya hemos llegado a los umbrales de tu propia generación, me gustaría que comenzaras tratando -testimonialmente - sobre lo que se enseñaba en la Escuela de Arquitectura de Madrid cuando tú estabas estudiando.

A. F. A. Los arquitectos que empezamos los estudios durante los años cuarenta y nueve y cincuenta nos encontramos con la paradoja de que nos habían formado con aproximaciones a una orientación clásica (antes de Vitruvio y después de Palladio), orientación que teníamos que abandonar al ingresar en la Escuela. Iniciamos la carrera dando un salto en el vacío de casi cuatro siglos: de los tratadistas clásicos a Mies van der Rohe sin mayor reflexión, lo cual producía naturalmente una frustración y un desconcierto. De pronto nos enteramos DE que había que clausurar la historia, la arquitectura moderna no creía en la historia, ¿quién nos podrá explicar que veintidós años después tendríamos que recuperar todo lo que nos negaron?

Aparecían entonces los primeros libros: Le Corbusier, Adolf Loos, F. Ll. Wright. Había que enfrentarse a todos estos nuevos nombres sin referencias ni tradiciones. Pero como de alguna manera había que traducir esos modelos racionalistas muy elementales y simples, se tuvo que acudir al ejemplo de los maestros: las imágenes y no el espacio de Mies van der Rohe, Le Corbusier, Walter Gropius, etc., eran los modelos que copiábamos, pero sin saber nada sobre los fundamentos que los justificaban. La magnífica biblioteca de la Escuela de Madrid apenas se utilizaba.

\section{LAS VICISITUDES DE UNA GENERACIÓN DRAMÁTICA}

F. C. S. ¿Cómo se sitúa tu generación en el contexto de la arquitectura española de aquel momento?

A. F. A. En cierto sentido, la generación anterior -la de Corrales, Molezún, Oiza, Sota, Cano, etc.- había hecho de generación puente entre la ruptura que había significado la guerra y las corrientes racionalistas anteriores. Tras ellos aparece una nueva generación de arquitectos que intentaba romper o evolucionar 
hacia unos modelos que encajen mejor con el ideal del arquitecto-artista, por llamarlo de alguna manera. De hecho, el arquitecto racionalista está más volcado hacia la tecnología e implementa la función como un elemento básico de la organización del espacio. Nuestra generación aparece en medio de otras corrientes y recurre de nuevo a los modelos extranjeros; principalmente F. Ll. Wright y Alvar Aalto. Este último era, sin embargo, más asequible para una realidad como la española, su país tenía una escala de referencia más próxima a nuestros problemas. Aunque quiero subrayar que las posibilidades de traspasar estos modelos a la realidad fueron muy pocas, ni las circunstancias, ni la capacidad de gestión de nuestra burocracia eran propicia a este tipo de operaciones culturales.

F. C. S. Tu generación, por otra parte, está marcada por una especie de destino dramático: pretende desarrollar un sentido crítico nuevo justo en el momento en que se dispara el boom del desarrollo, cuyas exigencias constructivas no reconocen ningún límite moral ni estético. Por otra parte, tu generación surge dentro de una oleada de esperanza en un cambio político y se corresponde con otras tendencias renovadoras en campos culturales muy diversos. ¿Qué es lo que pasó exactamente?

A. F. A. Efectivamente, aparece una serie de episodios de ruptura en todos los niveles, que trataba de configurar un lenguaje personal desde los más diferentes sectores. Es el momento de revistas como Theoría o Acento Cultural, etc. también el de una serie de individualidades y grupos de vanguardia como Luis de Pablo, Cristóbal Halffter, Sánchez Ferlosio, los componentes de El Paso, etc. Frente a estas propuestas surge la realidad impresionante del desarrollo, que afecta especialmente, como dices, a la arquitectura. El arquitecto, en la medida en que pretendiera objetivar y controlar la calidad del producto construido, desaparece; su función será postergada, o se integra o se margina, este es su dilema. La integración desarrollará otro tipo de profesional que trabajará sin reparos en dar fórmulas técnicas para este desarrollo especulativo. La consecuencia de todo esto supone entrar en un proceso de degradación que afecta no solo a lo que se proyecta y construye. El organismo construido de la ciudad sentirá de modo dramático estos episodios. Estas minorías se refugian, sobre todo los más jóvenes, en la erudición y el conocimiento de una arquitectura que rara vez estará presente en la escena de la ciudad. 
F. C. S. Marginados por el fenómeno de especulación inmobiliaria, ¿qué papel pudisteis desempeñar aquellos arquitectos que, como tú, no renunciasteis a una actitud crítica?

A. F. A. Estas minorías no tienen apenas protagonismo en la ciudad. La situación, por consiguiente, resultaba muy frustrante: desde luego hay que puntualizar también «el valor de la renuncia» de esas vanguardias: muchas de estas actitudes de ruptura surgieron más que como enfrentamiento al sistema como producto de una rebeldía típica de la mala conciencia burguesa, por un cansancio frente a los estereotipos arquitectónicos, por una evolución, natural, por una búsqueda de identidad personal constantes en fin del arquitecto burgués.

F. C. S. Pero ya que no pudisteis construir tal y como hubieseis deseado, ¿lograsteis al menos integraros, con vuestras ideas y proyectos condenados a la utopía por las circunstancias, en una alternativa política de futuro, que, en vuestro caso, era necesariamente de izquierda?

A. F. A. Con respecto a la arquitectura la izquierda no parece tener necesidad del espacio. En el fondo, nuestros partidos de izquierda no están implicados en una opción política, sino administrativa. Me refiero aquí a un sentido de la política como planificación. Nuestra izquierda, y pido disculpas por la generalización, en efecto, debió ser capaz de explotar las posibilidades de una tradición: haber elegido a profesionales con talento no solo con talante político para suplir en parte el vacío cultural del antiguo régimen, no lo han hecho, tendrán sus razones, solo parece preocuparles las normas y no la capacidad de proyectar. No hay, pues, una filosofía sobre qué tipo de ciudad hay que construir. Un pensamiento tecnocrático más que dialéctico parece invadir los presupuestos ideológicos y las consignas en torno a la arquitectura de la ciudad y a la ciudad misma.

\section{LA ARQUITECTURA DE LOS AÑOS SETENTA}

Y LAS EXPECTATIVAS DE FUTURO

F. C. S. Tras la barbarie constructiva de los años sesenta, en la década siguiente se aprecia un cierto cambio en el sentido de que comienza a verse, en algunas zonas muy concretas, una 
especie de promoción de arquitectura de «calidad». Este es el caso, por ejemplo, de la Castellana, con todas las salvedades que se quieran. ¿Qué significación le das a este fenómeno?

A. F. A. La arquitectura en España sigue el ritmo del desarrollo económico del país. En los setenta se mantienen sustancialmente los esquemas de la época anterior, aunque quizá se insinúa un cambio de forma en la imagen de la arquitectura. Este cambio fue provocado por un salto cualitativo desde el punto de vista del lenguaje arquitectónico como consecuencia de la crisis del Movimiento Moderno, que ya era manipulado descaradamente por los agentes de la especulación inmobiliaria. El capitalismo monopolista es sustancial con una especulación a gran escala. En España, se hace patente este cambio en el modo de producir el espacio de la ciudad. El rol del arquitecto pasa entonces a un segundo plano y toma el protagonismo, lo detenta, el urbanista. No obstante, los arquitectos no desean abandonar su papel y en los primeros diseños urbanos seguirán siendo los que de algún modo formalizan planes ideales. En España en raras ocasiones un plan ha servido para algo más que para la justificación política del ministro de turno. La formación del urbanista riguroso es muy superior a la del arquitecto. Ahora bien, respecto a lo que señalabas de un cierto cambio en algunas formas, creo que respondía a un nuevo tipo de comercialización de la arquitectura como creo que respondía a un nuevo tipo de comercialización de la arquitectura como mercancía, las nuevas formas comienzan a generar plusvalía. De manera que lo que se promociona es a los diseñadores escenográficos más que a los arquitectos. Esto no excluye que algunos arquitectos hayan realizado obras de indudable calidad. Formalmente la capacidad de innovación sigue la tradicional dependencia de modelos extranjeros, en su mayor parte italianos, esta tendencia es una constante historia de manera muy concreta desde el Renacimiento, de modo que esta invasión que soportamos de los modelos milaneses, venecianos o romanos, forma parte de nuestra vieja tradición de importar y reproducir las conquistas espaciales y formales italianas. La dependencia económica de EE. UU. Obliga, como es natural, a simultanear modelos americanos, pues el capital que construye hoy sus espacios tiende a unificar sus tipologías arquitectónicas, por eso no nos debe extrañar la similitud formal de estos proyectos con respecto a las construcciones norteamericanas. 
F. C. S. Ahora que están tan de actualidad esas exposiciones sobre «los ochenta», como especie de apuestas premonitorias sobre lo que viene, quisiera que me hablaras sobre cómo ves tú el futuro de nuestra arquitectura, naturalmente a partir de lo que están haciendo nuestros arquitectos más jóvenes.

A. F. A. En los últimos cinco años se ha producido una convergencia hacia lo que se ha dado en llamar la recuperación de la historia. Esta vuelta a la historia en cuanto a la arquitectura se refiere comenzó por la preocupación de recuperar ciertos modelos y propuestas de los arquitectos revolucionarios de la Ilustración, cubrir con imágenes el vacío formal de la crítica de los sesenta, introducir un orden, recuperar lo específico de la arquitectura, etc... Su consecuencia más inmediata fue apoyarse en la norma neoclásica, pero el movimiento se ha hecho cada vez más amplio y ecléctico. Personalmente creo que se trata de un movimiento de corte escolástico nacido en el seno de sectores críticos, marxistas y pseudomarxistas, que intentan revisar los procesos de producción de la arquitectura desde el vacío que dejó la ahistoricidad del Movimiento Moderno, algunos desde los esquemas de la lucha de clases, otros desde los valores del significado de las formas. En el fondo esta recuperación ideológica es, en general, formal: se entretiene en valores compositivos, pero no se modifican los contenidos. Nuestra sociedad actual dispone de unos mecanismos de explotación tan bien organizados que hasta los presupuestos de una ideología aparentemente revolucionaria pueden ser asimilados y generar su correspondiente plusvalía. La historia para alguno de estos grupos se ha transformado en una mercancía rentable.

Estamos asistiendo a la clausura de unos postulados arquitectónicos que entroncan y se nutren de principios iluministas, y de las utopías socialistas de finales del xix. ¿Esperanzas? Un ecologismo embrionario, preocupado tanto por la conservación de la naturaleza como por la interpretación y transformación de la historia, que hay que desear que consiga paralizar el crecimiento indiscriminado. 


\section{LA EXPERIENCIA DE FERNÁNDEZ ALBA COMO ARQUITECTO}

F. C. S. Tras haberte estado preguntando sobre tus ideas acerca de la evolución histórica de la arquitectura española contemporánea, quisiera que ahora nos centráramos sobre tu personal experiencia como arquitecto. ¿Cuándo y cómo comienzas a construir?

A. F. A. Nada más terminar la carrera (1957) construyo una pequeña casa en Salamanca que, a pesar de su escasa importancia, produce cierta polémica. Estaba situada en una zona histórica de la ciudad y me esforcé por respetar el contexto donde se ubicaba, aunque sin añadirle la ornamentación plateresca que requerían las ordenanzas. En Madrid comienzo realizando dos casas: una en la calle Martín de los Heros, que básicamente se inspira en el funcionalismo de Mies, y otra en la calle de Hilarión Eslava, más próxima a la temática compositiva de Aalto. En ambos proyectos la escalera sería el elemento más significativo desde un análisis espacial.

F. C. S. ¿En qué etapas y con qué obras representativas dividirías tu trayectoria arquitectónica?

A. F. A. La primera se podría contemplar aproximadamente, desde 1957 a 1965; está caracterizada por la influencia de las corrientes de recuperación de la arquitectura posrracionalista y por el proceso que va desde el racionalismo a las corrientes orgánicas. Es una época de utilización de los nuevos materiales como el hormigón. Para explicarla más concretamente me puedo servir de tres ejemplos: en 1958-59, realizo en Madrid el Colegio de Ntra. Sra. Santa María. Este proyecto me va a permitir entroncar con los planteamientos pedagógicos de la Institución Libre de Enseñanza. Aprovechando la colaboración verdaderamente ejemplar del artista Martín Chirino y de las directoras del centro, Josefa Benítez y Mani Segura. Se trataba de dar una máxima funcionalidad pedagógica. Creo que la escala del niño quedó muy patente. Respecto al lenguaje formal, la obra es ecléctica, participa de un racionalismo decantado y de algunas acotaciones orgánica.

En 1962 vuelvo a realizar otro colegio, esta vez para una comunidad de religiosos franceses: el Colegio de Monfort en Loeches (1964). Mi intención fue acentuar los apartados orgánicos 
a la vez que trataba de incorporar el edificio con el paisaje. Lo concibo como una especie de monte de barro aprovechando ciertos elementos extraídos de la arquitectura popular, y enfatizando los vacíos espaciales, claustros y patios. Finalmente, el tercer ejemplo de este período es el de la realización de un convento de clausura en Salamanca -Convento del Rollo (I962) -, aquí me muevo dentro de unos planteamientos modestos de una temática compositiva más libre. Los principios orgánicos se acentúan en la planta de la pequeña capilla, dentro de una trama cartesiana, y la luz y el tratamiento de los tránsitos y espacios interiores siguen la tradición hispanoárabe. El segundo período de mis trabajos se desarrolla en un tiempo que coincide con el declive de la ideología del Movimiento Moderno. Durante esta época me presento a unos catorce o quince concursos nacionales e internacionales sin resultados satisfactorios, salvo ese segundo premio de consolación que obtengo en el concurso del Palacio de Congresos y Exposiciones de Madrid. Es un momento de crisis general, marcada por los acontecimientos de Mayo del 68 . Dejo durante dos años mi actividad docente en la Escuela y me integro .en otras actividades como profesor invitado en algunas escuelas extranjeras. Así como mi relación con el grupo que Fullaondo aglutina de modo esporádico en torno a Nueva Forma. La promoción en Madrid de un centro para las enseñanzas del diseño, publicaciones, etc. Como obras más significativas de este período te señalaría la del concurso para el ayuntamiento de Ámsterdam (1968), en el que intento un encuentro de alternativa barroca por vía de las últimas obras de Miguel Ángel. En estos trabajos existe un predominio de la expresión monumental frente al contenido interior, una negación del espacio, son propuestas de contenedores expresionistas, el espacio de la arquitectura ya tiene otra dimensión. En Salamanca, vuelvo sobre el tema de los espacios para la soledad con una obra para la orden fundada por Santa Teresa: el Carmelo de San José (1969).

La construcción de estos conventos era como un desafío, suponía crear un espacio para unas comunidades cuyo tiempo era de otra época, una comunidad de clausura con principios religiosos del siglo XVI. Al fin de aliviar estas formas de vida, se dotó a estas comunidades contemplativas, que carecían de ocupación concreta y veían comprometida su supervivencia, de unas instalaciones, talleres de costura, encuadernación y 
pequeña imprenta, que les permitiera dar el salto a una sociedad industrial, esta experiencia de diseñar los contenidos antes que las formas me reveló el futuro papel de los arquitectos. Formalmente traté de introducir un lenguaje fabril, próximo al mundo de la máquina. En cierta manera, supuso una revisión romántica de ciertos aspectos del Movimiento Moderno que por diversos motivos no había podido verificar en los proyectos no construidos. Esta obra refleja con precisión que la forma física de cada comunidad o grupo organiza su espacio de acuerdo con sus necesidades psicológicas para supervivir.

F. C. S. ¿Por qué no hablas algo sobre la última etapa, haciendo hincapié sobre todo en edificios como la Biblioteca de Cultura Hispánica o el Centro de Datos del Instituto Geográfico y Catastral?

A. F. A. Antes, si me permites, quisiera decir algo sobre otra obra salamantina: el Colegio Mayor Hernán Cortés (I97I), asentado en lo que fueron las antiguas murallas de la ciudad. Proyecto y construcción que intentan formular una sintaxis de lo antiguo, fundamentando su volumetría en su prioridad histórica, recuperando la memoria del espacio perdido, la búsqueda no está orientada a reproducir una volumétrica plástica monumental, sino a integrar nuevos contenidos urbanos en el paisaje renovado de la ciudad. La obra a la que te refieres con tu pregunta está proyectada en I 964 -la Biblioteca de Cultura Hispánica-, realizada en colaboración con José Luis Fernández del Amo y José Ibáñez, que se construye en I975. El diseño de sus plantas recorre aún el trazado de las viejas corrientes orgánicas, tres cuerpos muy diferenciados de usos que pretenden significar sus respectivas funciones: el silo de libros, las dependencias administrativas y las salas de lectura. La relación entre forma y significado fue una intención muy decisiva en esta propuesta.

Respecto al Centro de Datos del Instituto Geográfico Nacional creo que supone una indagación sobre aquel aserto de que «toda función tiene su estructura», edificio que trata de asimilar el lenguaje del actual Instituto; dentro del programa de usos requeridos en esta ampliación. Este contenedor de datos evidencia algo que el trabajo del arquitecto percibe con bastante claridad y es que los aspectos formales de la arquitectura deben representar los sistemas funcionales que constituyen el contenido espacial 
del edificio. La relación icónica en la historia de la construcción es un hecho de gran importancia, lo fue en la antigüedad y lo sigue siendo en nuestro tiempo.

F. C. S. ¿Cuál ha sido tu último proyecto?

A. F. A. El último proyecto es de 1977 , el tema es un centro para minusválidos a las afueras de Madrid, dependiente de la Compañía Telefónica. Se trata de una obra muy interesante por su carácter experimental y su elaboración con un equipo interdisciplinar. El centro debe servir para el tratamiento, seguimiento y diagnóstico de minusválidos en toda su patología. Aquí la arquitectura se comporta como un objeto intermedio, la forma del espacio tiene que poseer una analogía estructural con el contenido terapéutico y a su vez la solución técnica debe ser coherente con la forma. Pueden intervenir formas y espacios convencionales y de hecho creo que intervienen, pero no deben dominar, configurar un espacio neutro es uno de los temas más complejos para el arquitecto, atraído casi siempre por la fruición de las formas. Atomizado en su composición por los diferentes usos, es un conjunto que intenta articularse y coordinar todos los componentes espaciales más relevantes. El espacio de la arquitectura es una función de totalidad y no de apartados concretos.

\section{NuEvo BIZANCIO}

F. C. S. Como última cuestión panorámica de esta entrevista no quisiera que dejáramos sin tocar la situación en la que se encuentra la arquitectura actual. Ya has hecho muchas referencias al tema en esta conversación, pero me gustaría volver sobre ello directamente, aunque sea de manera sintética.

A. F. A. En la actualidad, nos encontramos ante un dilema que me recuerda bastante al que se produce en el siglo pasado. La renovación de la arquitectura a partir de los aspectos formales con una indagación de la forma de carácter fundamentalmente romántico. Hoy nos encontramos a finales del siglo $\mathrm{XX}$ con la necesidad de recuperar la especificidad de lo arquitectónico en un período de transición como es el nuestro, pero las disciplinas aisladas en nuestros días creo que no tienen gran porvenir. Algunos se esfuerzan y obtienen un éxito considerable en ratificar la forma como solución y respuesta, aunque cada 
vez se alejen más de los problemas concretos. Se hace imprescindible establecer unos términos arquitectónicos que nos permitan entendernos, muy lejos de estos bizantinismos gráficos.

No podemos olvidar que en la actual estructura capitalista que vivimos la arquitectura es un modelo dependiente y no autónomo para producir el espacio de la ciudad.

F. C. S. Como última pregunta, quiero saber tu opinión sobre esa famosa frase de un arquitecto que tú admiras: L. I. Kahn. Exactamente era así: «Puede decirse que las máquinas son funcionales; que las bicicletas son funcionales; que las fábricas de cerveza son funcionales, pero no todos los edificios son funcionales». Esta frase la relaciono con la divertida ironía con la que Charles Jencks, profeta del posmoderno, se despacha la «forma univalente» de Mies van der Rohe y sus discípulos americanos, esta vez acusados de despreciar el viejo tema del decorum con su gramática universal ignorante del lugar y la función del edificio...

A. F. A. Creo que vivimos una fase donde el método que predomina es lo que pudiéramos denominar el método del funcionalismo delirante: la alianza por un lado con las fuerzas productivas y por otro con el academicismo oportunista, son factores que, producen una arquitectura disipada, aunque a veces la disipación pueda terminar componiendo unas formas y unos proyectos de general admiración. Pero observando algo más sus cualidades arquitectónicas podríamos encontrar la debilidad de sus espacios producto de la caligrafía intimista que los alberga y que producen a mi juicio una espacialidad casi alucinatoria.

La frase de Kahn fuera de su contexto explica poco o nada, su justificación tiene un tiempo y lugar concretos donde la función mal entendida hacía los estragos correspondientes; hoy este funcionalismo incoberente que tan desmesuradamente se difunde, sirve de cobertura para construir el espacio de nuestras ciudades y depende directamente del capitalismo monopolista, el más inofensivo se refugia en las academias y en las escuelas, ambos reproducen la patología de una sociedad enferma, en cuya arquitectura se contempla como en un espejo. 